P-ISSN: 2615-1723

E-ISSN: 2615-1766

April 2019
Jurnal Riset Pendidikan Dasar

02 (1), (2019) 41-47

Submitted: Februari, Accepted Maret, Published: April

\title{
PENGARUHMULTIMEDIATERHADAP HASIL BELAJAR IPS KELAS V SD NEGERI 34 LIBURENG KECAMATAN TONDONG TALLASA KABUPATEN PANGKEP
}

\section{Syarifah Nur Fajrin}

Program Studi Pendidikan Guru Sekolah Dasar, Fakultas Keguruan dan Ilmu Pendidikan, Universitas Islam Makassar

*Korespondensi. E-mail : Syarifahnurfajrin@uim-makassar.ac.id

\begin{abstract}
Abstrak
Penelitian ini bertujuan untuk mengetahui pengaruh multimedia pembelajaran terhadap hasil belajar IPS siswa kelas V SD Negeri 34 Libureng Kecamatan Tondong Tallasa Kabupaten Pangkep. Penelitian ini menggunakan penelitian kuantitatif dengan jenis penelitian ini ialah penelitian pra-eksperimen (praeksprimen design).Desain penelitian ini menggunakan The One Group Pretest Posttest. Adapunpopulasi penelitian ini adalah semua siswaI - VI SD Negeri 34 Libureng kecamatan tondong tallasa kapupaten pangkep. Sampel dalam penelitian diambil dengan menggunakan teknik sampling Non Probabily Sampling yang meliputi Sampling Purposve. Sampel yang digunakan dalam penelitian ini yaitu kelas Vdengan jumlah populasi sebanyak 14 siswa SD Negeri 34 Libureng kecamatan tondong tallasa kapupaten pangkep, sebagai kelas eksperimen.Berdasarkan uji hipotesis yang telah dilakukan dapat disimpulkan bahwa multimedia pembelajaran berpengaruh terhadap hasil belajar IPS setelah diperoleh $\mathrm{t}_{\mathrm{Hitung}}=5,36$ dan $\mathrm{t}_{\text {Tabel }}=$ 2,16 maka diperoleh $t_{\text {Hitung }}>t_{\text {Tabel }}$ atau 5,36 $>2$,16.Makadapat disimpuulkan bahwa hasil penelitian ini menunjukkan bahwa terdapat pengaruh dari penggunaan multimedia pembelajaran terhadap hasil belajar IPS siswa kelas V SD Negeri 34 Libureng Kecamatan Tondong Tallasa Kabupaten Pangkep.
\end{abstract}

Kata Kunci : Multimedia, Hasil Belajar, IPS

\section{THE INFLUENCE MULTIMEDIA OF STUDENT LEARNING SOCIAL SCIENCE CLASS V SDN 34 LIBURONG TONDONG TALLASA PANGKEP REGENCY}

\begin{abstract}
This study aims to study multimedia learning on social studies learning in the fifth grade students of 34 Public Elementary School 34 Libureng, Tondong Tallasa, Pangkep Regency. This study uses quantitative research with this type of research is pre-experimental research (pre-experimental design). The design of this study uses The One Group Pretest Posttest. Everyone learns this is all students I - VI SD Negeri 34 Libureng, tondong tallasa sub-district, pangkep regency. Samples in the study were taken using the Non Probable Sampling sampling technique provided by Purposve Sampling. The sample used in this study was class $V$ with the number of participants as many as 14 students from 34 Public Elementary School Libureng, Tondong Tallasa Pangkep, as the experimental class. Based on the hypothesis test that has been done, it can conclude the multimedia learning obtained from social studies learning after obtaining t count $=5.36$ and $t$ table $=2.16$, then $t$ count $>t$ table or $5.36>2.16$. Then it can be concluded that the results of this study are intended to use multimedia learning on the learning outcomes of the fifth grade students of 34 Public Elementary Schools in Tondong Tallasa, Pangkep Regency.
\end{abstract}

Keyword : Multimedia, Students Learning, IPS

Copyright $\odot 2019$, JRPD, ISSN 2615 - 1723 (Print), ISSN 2615 - 1766 (Online 


\section{PENDAHULUAN}

Pendidikan merupakan suatu yang sangat berharga dan dibutuhkan dalam rangka menghadapi tantangan di masa depan. Pendidikan di masa depan memiliki peranan yang sangat fundamental dimana cita-cita suatu bangsa dan negara dapat diraih. Dalam Pasal 3 Undang-Undang Nomor 20 Tahun 2003 tentang Sistem Pendidikan Nasional mengatur:

Pendidikan Nasional berfungsi untuk mengembangkan kemampuan dan membentuk watak serta peradaban bangsa yang bermartabat dalam rangka mencerdaskan kehidupan bangsa bertujuan untuk berkembangnya potensipotensi Siswa agar menjadi manusia yang beriman dan bertaqwa kepada Tuhan Yang Maha Esa, berakhlak mulia, sehat, berilmu, cakap, kreatif, mandiri dan menjadi warga negara yang demokrasi serta bertanggungjawab.

Berdasarkan pernyataan di atas, tujuan dan fungsi pendidikan adalah untuk memberikan bekal yang diperlukan oleh siswa dalam kehidupan sehari-hari. Melalui pendidikan siswa diharapkan mendapatkan hasil belajar yang baik. Tercapainya tujuan Pendidikan Nasional dapat dilihat dari hasil belajar, perubahan perilaku, dan penguasaan keterampilan di bidang tertentu. Keberhasilan itu secara akademik dikaitkan dengan tinggi rendahnya nilai yang dicapai siswa, daya serap siswa dan prestasi siswa. Pembelajaran IPS tidak kalah pentingnya untuk menggunakan media pembelajaran karena Ilmu pengetahuan Sosial (IPS) merupakan mata pelajaran yang terdapat di Sekolah Dasar yang dianggap penting untuk bekal siswa. Ilmu pengetahuan Sosial merupakan mata pelajaran yang bersumber dari kehidupan sosial masyarakat yang diseleksi dengan menggunakan konsepkonsep ilmu sosial yang digunakan untuk kepentingan pembelajaran. Tujuan dari pendidikan IPS adalah untuk membentuk siswa yang baik dan mampu berpikir secara cerdas. Maksudnya bahwa siswa mampu menyeleksi, mengadaptasi, dan mengaplikasikan nilai-nilai yang ada dalam agama, kebudayaan, negara dan negara-negara lain.

Berdasarkan hasil observasi awal yang dilakukan peneliti, ternyata penggunaan media dalam pembelajaran IPS masih kurang dimanfaatkan oleh guru-guru di tingkat sekolah dasar (SD) khususnya di SD Negeri 34 Libureng Kecamatan Tondong Tallasa Kabupaten Pangkep. Penggunaan media dalam kegiatan pembelajaran masih menggunakan media sederhana yaitu media gambar. Kegiatan media pembelajaran yang kurang dimanfaatkan tersebut menyebabkan pembelajaran monoton sehingga siswa merasa bosan dalam belajar, mengganggu teman, bercerita dengan teman, dan bermain-main ketika proses pembelajaran, hal tersebut mempengaruhi tingkat penguasaan siswa terhadap suatu konsep materi yang sedang dipelajari. Sehingga berdampak pada hasil belajar siswa yang rendah.

Guru diharapkan dapat mengkombinasikan suatu konsep kepada siswa dengan baik agar dapat dipahami dan dikuasai sepenuhnya oleh siswa, akan tetapi tidak semua siswa dapat menguasai konsep dengan baik. Hal ini yang menyebabkan rendahnya hasil belajar IPS. Kenyataan ini mendorong perlunya penggunaan media pembelajaran yang menarik dan menyenangkan. Penggunaan bahasa visual, gaya bahasa,pada multimedia dapat menarik perhatian siswa untuk belajar dengan gaya yang berbeda dari biasanya,Multimedia merupakan penyampaian ide, gagasan, dan bahkan merupakan kebebasan berpikir. Bentuk multimedia yang berupa tulisan, suara, gambar, animasi dan video dapat memudahkan siswa dalam menguasai konsepkonsep dalam Ilmu Pengetahuan Sosial (IPS) 
dan dapat meningkatkan hasil belajar siswa agar tercapainya tujuan pembelajaran IPS.

Diketahui IPS merupakan mata pembelajaran yang mempelajari kehidupan manusia oleh karena itu perluadanya pengunaan media yang efektif dalam pembelajaran sekitar $85 \%$ siswa hanya mendegarkan penjelasan guru sehingga hal ini menjadi salah satu faktor kurang efektifnya pembelajaran di kelas maka perlu mengunakan multimedia untuk meningkatkan hasil belajar siswa. Berdasarkan data penilaian Guru menunjukan bahwa hasil belajar IPS Siswa di SD Negeri 34 Libureng Kecamatan Tondong Tallasa Kabupaten Pangkep masih di bawah standar Kriteria Ketuntasan Minimal (KKM). Di mana Standar KKM yang ditentukan untuk mata pelajaran IPS adalah 60. Maka peneliti tertarik untuk melakukan penelitian dengan judul "Pengaruh Multimedia Terhadap Hasil Belajar IPS Kelas V SD Negeri 34 Libureng Kecamatan Tondong tallasa Kabupaten Pangkep".Dalam penggunaan Multimedia yang akan dipakai oleh peneliti yaitu mediayang dibuat sendiri.

\section{METODE}

Penelitian ini menggunakan penelitian kuantitatif dengan jenis penelitian ini ialah penelitian pra-eksperimen (pra-eksprimen design).Desain penelitian ini menggunakan The One Group Pretest Posttest. Sebelum diberi perlakuan, kelompok diberi pre-test. Setelah hasil pre-test diperoleh maka kelompok baru diberi treatmen.dengan demikian populasi penelitian ini adalah semua siswaI - VI SD Negeri 34 Libureng kecamatan tondong tallasa kapupaten pangkep.Menurut Sugiyono (2016:124) Sampel adalah bagian dari jumlah dan karakteristik yang dimiliki oleh populasi. Sampel dalam penelitian diambil dengan menggunakan teknik sampling Non Probabily Sampling yang meliputi Sampling Purposve. Sampel ini adalah dengan menggunakan teknik penentuan sampel dengan pertimbangan tertentu.

Sampel yang digunakan dalam penelitian ini adalah seluruh jumlah dari populasi (sampel populasi) yaitu kelas Vdengan jumlah populasi sebanyak 14 siswa SD Negeri 34 Libureng kecamatan tondong tallasa kapupaten pangkep, sebagai kelas eksperimen. Salah satu pertimbangan yang mendasari peneliti mengambil sampel dari seluruh populasi kelas V karena rata-rata hasil belajar IPS siswa belum memenuhi Kriteria Ketuntasan Minimal (KKM) dan siswa telah mampu untuk menganalisis dan berpikir kritis terhadap suatu materi.

\section{HASIL DAN PEMBAHASAN}

\section{Hasil Observasi}

Sesuai dengan kriteria aktivitas Siswa yang telah ditentukan peneliti yaitu, Siswa dikatakan aktif dalam proses pembelajaran jika jumlah Siswa yang aktif $\geq 70 \%$ baik untuk aktivitas Siswa perindikator maupun rata-rata aktivitas Siswa, dari hasil pengamatan rata-rata persentase jumlah Siswa yang aktif melakukan aktivitas yang diharapkan yaitu mencapai $74,83 \%$ sehingga dapat disimpulkan bahwa aktivitas Siswa dalam proses pembelajaran IPSdengan menggunakan multimediapembelajaranyang telah mencapai kriteria aktif.

\section{Tes Hasil Belajar}

a. Tes Awal (Pretest)

Berdasarkan hasil penelitian yang dilakukan oleh peneliti di SDNegeri 34 Libureng Kecamatan Tondog Tallasa Kabupaten Pangkep, maka diperoleh data-data yang dikumpulkan melalui instrumen tes sehingga dapat diketahui hasil belajar IPSSiswa berupa nilai dari Kelas V SD Negeri 34 libureng Kecamatan Tondong Tallasa Kabupaten Pangkep. 
Jurnal Riset Pendidikan Dasar, 02 (1), April 2019 (41-47)

Syarifah Nur Fajrin

Dari hasil perhitungan di atas maka diperoleh nilai rata-rata dari hasil belajar IPS Siswa Kelas V SD Negeri 34 libureng Kecamatan Tondong Tallasa Kabupaten Pangkep sebelum penerapan multimedia pembelajaranyaitu 61,64 dengan kategori sedang.

Apabila dikaitkan dengan indikator kriteria ketuntasan hasil belajar IPSyang ditentukan oleh peneliti, dapat disimpulkan bahwa hasil belajar IPSSiswa Kelas V SD Negeri 34 libureng Kecamatan Tondong Tallasa Kabupaten Pangkep, belum memenuhi kriteria ketuntasan hasil belajar secara klasikal, karena tidak adanya Siswa yang tuntas.

\section{b. Tes Akhir (Posttest)}

Selama penelitian berlangsung terjadi perubahan terhadap kelas setelah diberikan perlakuan. Perubahan tersebut berupa hasil belajar yang datanya diperoleh setelah diberikan posttest. Dari data hasil post-test di atas dapat diketahui bahwa nilai dari $\sum f x=$ 1018,77dan nilai dari $\mathrm{N}$ sendiri adalah 14 . Dari hasil perhitungan di atas maka diperoleh nilai rata-rata dari hasil belajar IPSSiswa Kelas V SD Negeri 34 libureng Kecamatan Tondong Tallasa Kabupaten Pangkep setelah penerapan multimedial pembelajaranyaitu 73,01. Adapun di kategorikan pada pedoman Departemen pendidikan dan kebudayaan (Depdikbud), dengan kategori tinggi.

\section{B. Analisis Data Hasil Penelitian}

Sesuai dengan hipotesis penelitian yakni "ada pengaruh dalam menggunakan multimediapembelajaran terhadap hasil belajar IPSpada Siswa kelas V SD Negeri 34 libureng Kecamatan Tondong Tallasa Kabupaten Pangkep, maka teknik yang digunakan untuk menguji hipotesis tersebut adalah teknik statistik inferensial dengan menggunakan uji-t.
Tabel 1 Analisis Skor Pretest dan Posttest

\begin{tabular}{|c|c|c|c|c|}
\hline No & T1 & $\mathrm{T} 2$ & $\mathrm{~d}=\mathrm{T} 2-\mathrm{T} 1$ & $d^{2}$ \\
\hline 1 & 57,5 & 56,67 & $-0,83$ & 0,69 \\
\hline 2 & 57,5 & 60,83 & 3,33 & 11,08 \\
\hline 3 & 64,6 & 81,67 & 17,07 & 291,38 \\
\hline 4 & 69.15 & 81,4 & 12,25 & 150,06 \\
\hline 5 & 59,6 & 73,9 & 14,3 & 204,49 \\
\hline 6 & 57,5 & 56,67 & $-0,83$ & 0,69 \\
\hline 7 & 60 & 58.07 & $-1,93$ & 3,72 \\
\hline 8 & 64,6 & 81,67 & 17,07 & 291,38 \\
\hline 9 & 61,65 & 79,83 & 18,18 & 330,51 \\
\hline 10 & 60 & 78,6 & 18,6 & 345,96 \\
\hline 11 & 66,65 & 83,07 & 16,42 & 269,62 \\
\hline 12 & 57,5 & 73,33 & 15,83 & 250,59 \\
\hline 13 & 57,5 & 76,67 & 19,17 & 367,49 \\
\hline 14 & 69,15 & 79.73 & 10,58 & 111,94 \\
\hline \multicolumn{3}{|c|}{ Jumlah } & 159,21 & 2629,6 \\
\hline
\end{tabular}

Keterangan:

$\mathrm{T} 1=$ Pretest

$\mathrm{T} 2=$ Posttest

$\mathrm{d}=$ jumlah dari gain $($ posttest - pretest $)$

$\mathrm{d}^{2}=$ jumlah dari gain setelah dikuadratkan

Langkah-langkah dalam pengujian hipotesis adalah sebagai berikut:

1. Mencari harga "Md" dengan menggunakan rumus:

$$
\begin{aligned}
& \mathrm{Md}=\frac{\sum d}{N} \\
& =\frac{159,21}{14} \\
& =11,37
\end{aligned}
$$

2. Mencari harga " $\sum X^{2} d "$ dengan menggunakan rumus:

$$
\begin{aligned}
\sum X^{2} d & =\sum d^{2}-\frac{\left(\sum d\right)^{2}}{N} \\
& =2629,6-\frac{(159,21)^{2}}{14} \\
& =2629,6-\frac{25347,82}{14} \\
& =2629,6-1810,56 \\
& =819,04
\end{aligned}
$$


3. Menentukan harga $t_{\text {Hitung }}$

$$
\begin{gathered}
\mathrm{t}=\frac{M d}{\sqrt{\frac{\sum X^{2} d}{N(N-1)}}} \\
\mathrm{t}=\frac{11,37}{\sqrt{\frac{819,04}{14(14-1)}}} \\
\mathrm{t}=\frac{11,37}{\sqrt{\frac{819,04}{182}}} \\
\mathrm{t}=\frac{11,37}{\sqrt{4,50}} \\
\mathrm{t}=\frac{11,37}{2,12} \\
\mathrm{t}=5,36
\end{gathered}
$$

4. Menentukan harga $t_{\text {Tabel }}$

Mencari $t_{\text {Tabel }}$ peneliti menggunakan table distribusi $\mathrm{t}$ dengan taraf signifikan $\alpha=0,05$ dan $d . b=N-1=14-1=13$ maka diperoleh $\mathrm{t}_{0,05}=2,16$ (lihat lampiran 17). Setelah diperoleh $t_{\text {Hitung }}=5,36$ dan $t_{\text {Tabel }}=2,16$ maka diperoleh $t_{\text {Hitung }}>t_{\text {Tabel }}$ atau 5,36 $>2,06$.

Sehingga dapat disimpulkan bahwa $\mathrm{H}_{0}$ ditolak dan $\mathrm{H}_{\mathrm{a}}$ diterima. Ini berarti bahwa ada pengaruh dalam menggunakan multimediapembelajaranterhadap hasil belajar IPS pada Siswa Kelas V SD Negeri 34 libureng Kecamatan Tondong Tallasa Kabupaten Pangkep.

\section{Pembahasan}

Berdasarkan hasil observasi terdapat perubahan pada Siswa yaitu pada awal kegiatan pembelajaran ada beberapa Siswa yang tidak memperhatikan selama pembelajaran berlangsung. Hal ini dapat dilihat pada pertemuan pertama siswa yang tidak memperhatikan sebanyak 4 orang, sedangkan pada pertemuan terakhir hanya 1 Siswa yang tidak memperhatikan pada saat pembelajaran berlangsung. Pada awal pertemuan, hanya sedikit Siswa yang aktif mengikuti pembelajaran. Akan tetapi sejalan dengan diberikannya penguatan verbal, Siswa mulai aktif pada setiap pertemuan.

Hasil observasi menunjukkan banyaknya jumlah Siswa yang menjawab pada saat diajukan pertanyaan dan siswa yang mengajukan diri untuk melakukan kegiatan pembelajaran. Siswa juga mulai aktif dan percaya diri untuk menyampaikan perasaan dan pendapatnya, mereka mengaku senang dan sangat menikmati kegiatan pembelajaran yang dilakukan sehingga termotivasi untuk mengikuti pelajaran. Proses Pembelajaran yang menyenangkan membuat Siswa tidak lagi keluar masuk pada saat Pembelajaran berlangsung dan tidak lagi merasa bosan ataupun tertekan ketika mengikuti proses Pembelajaran di kelas.tidak lagi merasa bosan ataupun tertekan ketika mengikuti proses Pembelajaran di kelas.

Berdasarkan hasilpretest, nilai rata-rata hasil belajar Siswa 61,64 dengan kategori yakni sangat rendah yaitu $0,00 \%$, rendah 0,00 $\%$, sedang $85,71 \%$, tinggi $14,29 \%$ dan sangat tingggi berada pada presentase $0,00 \%$. Melihat dari hasil presentase yang ada dapat dikatakan bahwa hasil belajar IPS Siswa sebelum diberikan multimedia pembelajarantergolong sangat rendah.

Nilai rata-rata hasil posttest setelah digunakan multimedia pembelajaran yaitu 73,01. Hal ini membuktikan bahwa hasil belajarposttest lebih baik dibanding dengan sebelum penggunaan multimedia pembelajaran. Selain itu persentasi kategori hasil belajar IPS Siswa juga meningkat yakni sangat tinggi yaitu $0,00 \%$, tinggi $71,43 \%$, sedang $28,57 \%$, rendah $0,00 \%$, dan sangat rendah berada pada presentase $0,00 \%$.

Berdasarkan hasil analisis statistik inferensial dengan menggunakan rumus uji $t$, dapat diketahui bahwa nilai $t_{\text {hitung }}$ sebesar 5,36 . Dengan frekuensi (dk) sebesar $14-1=13$, pada taraf signifikansi $5 \%$ diperoleh $t_{\text {tabel }}=$ 2 ,16. Oleh karena $t_{\text {hitung }}>t_{\text {tabel }}$ pada taraf 
signifikansi 0,05 , maka hipotesis nol $\left(\mathrm{H}_{0}\right)$ ditolak dan hipotesis alternative $\left(\mathrm{H}_{\mathrm{a}}\right)$ diterima yang berarti bahwa ada pengaruh dalam menggunakanmultimediapembelajaran terhadap hasil belajar IPS Siswa kelas V SD Negeri 34 libureng Kecamatan Tondong Tallasa Kabupaten Pangkep.

Berdasarkan hasil analisis statistik deskriptif dan statistik inferensial yang diperoleh serta hasil observasi yang telah dilakukan, dapat disimpulkan bahwa ada pengaruh dalam menggunakan multimediapembelajaran terhadap hasil belajar IPS Siswa kelas V SD Negeri 34 libureng Kecamatan Tondong Tallasa Kabupaten Pangkep.

\section{SIMPULAN}

Berdasarkan hasil penelitian dan pembahasan, maka penulis dapat mengambil simpulan bahwa pemberian penguatan sangat penting dalam kegiatan belajar mengajar, salah satunya yaitu multimedia pembelajaran. Guru memiliki peran penting dalam proses pembelajaran sehingga sudah semestinya guru menerapkanmultimedia pembelajaran untuk siswanya. multimedia pembelajaran yang diberikan tepat pada sasaran sehingga dapat menimbulkan dampak yang positif bagi Siswa, terutama dalam hasil belajarnya. Berdasarkan data yang diperoleh dapat disimpulkan bahwa secara umum hasil belajar IPS Kelas V SD Negeri 34 libureng Kecamatan Tondong Tallasa Kabupaten Pangkep, sebelum multimedia pembelajaran dikategorikan sangat rendah. Hal ini ditunjukkan dari hasil skor rata-rata yang diperoleh Siswa yaitu61,64.

Berdasarkan data yang diperoleh dapat disimpulkan bahwa secara umum hasil belajar IPS Kelas V SD Negeri 34 libureng Kecamatan Tondong Tallasa Kabupaten Pangkep, setelah menggunakanmultimedia pembelajaran dikategorikan tinggi. Hal ini ditunjukkan dari hasil skor rata-rata yang diperoleh Siswa yaitu
73,01. Berdasarkan uji hipotesis yang telah dilakukan dapat disimpulkan bahwa multimedia pembelajaran berpengaruh terhadap hasil belajar IPS setelah diperoleh $t_{\text {Hitung }}=5,36$ dan $t_{\text {Tabel }}=2,16$ maka diperoleh $t_{\text {Hitung }}>t_{\text {Tabel }}$ atau 5,36 $>2,16$.

\section{DAFTAR PUSTAKA}

Agina, A.M. (2003). The Advantages and Disadvantages of The Animation Technology in Education and Training.

Arsyad, A. (2013). Media Pembelajaran. Jakarta: Raja Grafindo Persada

Dimyati \& Mudjiono. (2002) Belajar dan Pembelajaran. Jakarta: RinekaCipta

Dimyati \& Mudjiono. (2010) Belajar dan Pembelajaran. Jakarta: RinekaCipta

Marissa. (2011). Komputer dan Media Pembelajaran. Jakarta: Unversitas Terbuka.

Oemar, H. (2003). Proses Belajar Mengajar Jakarta: PT Bumi Aksara

Sardjiyo. (2009). Pendidikan IPS di SD. Jakarta: Unversitas Terbuka.

Sapriya. (2009). Pendidikan IPS. Bandung: Remaja Rosdakarya

Sanjaya, W. (2006). Strategi Pembelajaran Berorientasi Standar Proses Pendidikan. Bandung: Kencana Prenada Media Group.

Slameto. (1995). Proses Belajar Pembelajaran. Bandung Kencana.

Sudiman, A.S. (2012). Media Pendidikan Pengertian, Pengembangan, dan Pemanfaatannya. Jakarta: Raja Grafindo Persada.

Sugiyono. (2016). Metode Penelitian Kombinasi (Mixed Methods). Bandung: Alfabeta.

Sudjana, N. (2013). Penilaian hasil proses belajar mengajar. Bandung PT. Remaja rusda karya

Supardi. (2011). Dasar-dasar Ilmu Sosial. Yogyakarta: Ombak 
Jurnal Riset Pendidikan Dasar, 02 (1), April 2019 (41-47)

Syarifah Nur Fajrin

Susanto, A. (2013). Teori Belajar \& Pembelajaran

di Sekolah Dasar. Jakarta: Kencana Prenada Group.

Susanto, A. (2016). Pengembangan Pembelajaran IPS di Sekolah Dasar. Jakarta: Prenadamedia Group.

Trianto.2012.Model Pembelajaran Terpadu : Konsep, Strategi danImplementasinya. Jakarta

Tulus, T. (2004). Peran Disiplin pada Prilaku dan Prestasi siswa. Jakarta: Grasindo.

Undang-Undang No. 20 Tahun 2003. Sistem pendidikan nasional.Jakarta Sisdiknas. 